\title{
Chlorophyll $a+b$ content in leaves of spring barley after MCPA and selected HILs application
}

\author{
Zawartość chlorofilu $a+b$ w liściach jęczmienia jarego \\ po zastosowaniu MCPA oraz wybranych HILs
}

\author{
Marcin Grobela*
}

\section{Summary}

The aim of the study was to examine the effect of spraying two herbicidal ionic liquid forms of MCPA (HILs - [Etq O-12][MCPA], [DDA] [MCPA]) on chlorophyll $a+b$ content in leaves of spring barley (Hordeum vulgare L.). Spectrophotometric method was used to measure chlorophyll $\mathrm{a}+\mathrm{b}$ content 24 and $72 \mathrm{~h}$ after fields were sprayed. The data was compared to controls that consisted of the treatments using a commercial formulation of MCPA as a salt or ester. The field studies revealed that after $24 \mathrm{~h}$ of MCPA as a salt spraying chlorophyll $\mathrm{a}+\mathrm{b}$ content in spring barley was lower by $12 \%$ and after $72 \mathrm{~h}$ by $18 \%$. The application of MCPA as an ester lowered the chlorophyll $a+b$ amount by just $9 \%$, as a HILs resulted in decrease by about $3 \%$ compared to control plots. The results do not confirm a significant impact on the content of photosynthetic pigments in spring barley, but they show that the application of HILS as an alternative herbicide can reduce the undesirable effects of MCPA.

Key words: chlorophyll; herbicidal ionic liquids; MCPA; spring barley

\section{Streszczenie}

Celem prowadzonych badań była spektrofotometryczna ocena zmian zawartości chlorofilu w liściach jęczmienia jarego po 24 i $72 \mathrm{~h}$ od zastosowanego opryskiwania powszechnie stosowanymi środkami ochrony roślin na bazie MCPA (Chwastox Extra 300 SL, Chwastox AS 600 EC) oraz wybranymi herbicydowymi cieczami jonowymi HILs ([Etq 0-12][MCPA], [DDA][MCPA]). Poziom chlorofilu a + b $\mathrm{w}$ jęczmieniu jarym po $24 \mathrm{~h}$, na który zaaplikowano MCPA w postaci soli był niższy o $12 \%$, a po $72 \mathrm{~h}$ aż o $18 \% \mathrm{w}$ porównaniu do stężenia barwników roślin z poletek kontrolnych. Po aplikacji MCPA w postaci estru zawartość chlorofilu a $+b$ również była niższa, ale tylko o około $9 \%$. Zabiegi przeprowadzone wyłącznie HILs powodowały jego bardzo małe spadki wynoszące około $3 \%$. Uzyskane wyniki nie potwierdzają istotnego wpływu stosowania MCPA na zawartość pigmentów fotosyntetycznych w jęczmieniu jarym, jednak pokazują, że aplikacja HILs jako herbicydu alternatywnego może ograniczyć niepożądane efekty jego działania.

Słowa kluczowe: chlorofil; herbicydowe ciecze jonowe; MCPA; jęczmień jary

Instytut Ochrony Roślin - Państwowy Instytut Badawczy

Władysława Węgorka 20, 60-318 Poznań

*corresponding author: grobela@iorpib.poznan.pl 


\section{Wstęp / Introduction}

Chlorofile to grupa barwników fotosyntetycznych występujących głównie w roślinach wyższych, glonach oraz cyjanobakteriach. Fotosynteza jest podstawowym procesem fizjologicznym roślin, od jej aktywności zależy m.in. wysokość uzyskanego plonu. Kluczową rolę w prawidłowym przebiegu fotosyntezy odgrywa zapotrzebowanie roślin na makro- i mikroelementy, a przede wszystkim magnez (Ceylan i wsp. 2016; Tatagiba i wsp. 2016; Tränkner i wsp. 2016) i żelazo, które jest aktywatorem syntezy chlorofilu (Politycka 2007). Na procesy fizjologiczne zachodzące w roślinach znaczący wpływ mogą wywierać także substancje czynne zawarte w powszechnie stosowanych środkach ochrony roślin. W zależności od ich budowy i właściwości mogą one prowadzić do zmian strukturalnych białek, lipidów, kwasów nukleinowych oraz chlorofilu, zaburzając prawidłowy przebieg niektórych szlaków metabolicznych (Ekmekci i Terzioglu 2005). W badaniach Wang i Zhou (2006) oraz Žaltauskaite i Brazaityte (2013) stwierdzono zmniejszoną zawartość chlorofilu w roślinach po zastosowaniu różnych herbicydów. W innych pracach autorzy przedstawiają różne zależności między zawartością chlorofilu w roślinach a stosowaniem herbicydów. Analizy prowadzone przez Łozowicką i wsp. (2016) pokazują, że stosowanie herbicydów zawierających w swoim składzie MCPA i dikambę spowodowało spadek zawartości chlorofilu w roślinach, jednakże łączne stosowanie herbicydu i fungicydu przyczyniało się do wzrostu jego stężenia w liściach trzech odmian pszenicy jarej. Natomiast Žaltauskaitė i Kišonaitė (2014) w swoich badaniach wykazali, że stosowanie MCPA przyczynia się do zmniejszenia suchej masy łodyg i korzeni pszenicy jarej, bez wywołania znaczącego wpływu na zawartość fotosyntetycznych pigmentów w tkankach roślinnych. Tatarková i wsp. (2013) przeprowadzili obserwacje, z których wynika, że obecność MCPA w glebie nie ma znaczącego wpływu na zawartość chlorofilu w liściach słonecznika.

Dużym zainteresowaniem w ostatnim czasie cieszą się tzw. herbicydowe ciecze jonowe (HILs), których stosowanie mogłoby wyeliminować negatywne skutki działania tradycyjnych środków ochrony roślin (Hough i wsp. 2007; Pernak i wsp. 2011; Shamshina i wsp. 2015). HILs charakteryzują się mniejszą mobilnością w glebie oraz wodach gruntowych, posiadają wysoką aktywność powierzchniową, co niweluje potrzebę stosowania adiuwantów lub surfaktantów, są bezpieczniejsze w stosowaniu, a dawka substancji czynnej, w porównaniu z obecnie stosowanymi herbicydami, może być znacząco obniżona przy zachowaniu ukierunkowanych właściwości biologicznych z wybranymi właściwościami chemicznymi i fizycznymi (Praczyk i wsp. 2012; Pernak i wsp. 2013; Grobela 2016).

Celem podjętych badań była ocena łącznej zawartości chlorofilu a i b w liściach jęczmienia jarego po zastosowaniu herbicydów na bazie MCPA w postaci soli i estru oraz wybranych herbicydowych cieczy jonowych. Badania zostały przeprowadzone w warunkach polowych.

\section{Materiały i metody / Materials and methods}

W badaniach zastosowano dostępne w handlu dwie formulacje MCPA: w postaci soli sodowo-potasowej [Chwastox Extra 300 SL (Ch300), producent Zakłady Chemiczne Organika-Sarzyna S.A. Nowa Sarzyna, Polska] oraz w postaci estru 2-etyloheksylowego [Chwastox AS 600 EC (Ch600), producent Zakłady Chemiczne Organika-Sarzyna S.A. Nowa Sarzyna, Polska], a także będące w fazie badań herbicydowe ciecze jonowe: [Etq O-12][MCPA] (ETQ) (4-chloro-2-metylofenoksy)octan ethoquadu O-12 oraz [DDA][MCPA] (DDA) (4-chloro-2-metylofenoksy)octan didecylodimetyloamoniowy. Herbicydowe ciecze jonowe zostały zsyntetyzowane w Zakładzie Technologii Chemicznej Politechniki Poznańskiej oraz opisane przez Pernaka i wsp. (2011).

Badania polowe prowadzone były w 2014 roku w Terenowej Stacji Doświadczalnej w Winnej Górze (E17²6', N52 $\left.{ }^{\circ} 12^{\prime}\right)$. Jęczmień jary (Hordeum vulgare L.) odmiany KWS Olof uprawiany był na poletkach doświadczalnych o powierzchni $16,5 \mathrm{~m}^{2}$. Doświadczenie założono w układzie losowanych bloków, w czterech powtórzeniach z uwzględnieniem poletek kontrolnych, na których nie stosowano opryskiwania. Jako substancje odniesienia zostały użyte handlowo dostępne herbicydy Ch300 oraz Ch600. Omawiane herbicydy oraz HILs aplikowano w takiej dawce, aby stężenie substancji czynnej było takie samo i wynosiło $900 \mathrm{~g} / \mathrm{ha}$. Roztwory stosowano $\mathrm{w}$ fazie rozwojowej BBCH 14 opryskiwaczem plecakowym Aporo (Poznań, Polska) wyposażonym w dysze płaskostrumieniowe TeeJet ${ }^{\circledR}$ DG110/02 (TeeJet Technologies, Wheaton, IL, USA) o wydajności 200 1/ha i ciśnieniu roboczym $0,3 \mathrm{MPa}$.

Rośliny do oznaczeń chlorofilu pobrano losowo z każdego poletka doświadczalnego. Analizie zostały poddane najmłodsze, w pełni rozwinięte liście. Zawartość chlorofilu oznaczona została zgodnie z metodą Arnona i wsp. (1956), z modyfikacją Lichtenthalera i Wellburna (1983). Do ok. $0,5 \mathrm{~g}$ schłodzonych liści dodano 5-10 $\mathrm{ml} \mathrm{80 \%}$ acetonu, ok. $0,1 \mathrm{~g} \mathrm{CaCO}_{3}$ i piasku kwarcowego, wszystko dokładnie roztarto $\mathrm{w}$ moździerzu, przeniesiono ilościowo i przesączono do kolby miarowej. Moździerz dokładnie przemyto małymi porcjami $80 \%$ acetonu. Końcową objętość przesączu ustalono na $50 \mathrm{ml}$. Oznaczenia zawartości chlorofilu dokonano przy pomocy spektrofotometru Unicam Heloios $£$ przy długościach fal: 645 oraz $663 \mathrm{~nm}$.

Wyniki zawartości chlorofilu a + b [mg/g ś.m.] obliczono wg wzoru:

$$
\left.\mathrm{C}_{\mathrm{chl}(\mathrm{a}+\mathrm{b})}=\left(8,02 \times \mathrm{A}_{(663)}+20,2 \times \mathrm{A}_{(645)}\right) \times((\mathrm{V} / 1000) \times \mathrm{w})\right)
$$

A 645-663 - wartość absorbancji mierzonej przy długości fali $645-663 \mathrm{~nm}$,

V - całkowita objętość ekstraktu [ml],

$\mathrm{w}$ - masa próbki [g],

8,02 i 20,2 - współczynnik przeliczeniowy.

Do wyznaczenia relacji między zawartością chlorofilu $\mathrm{w}$ liściach jęczmienia jarego, zastosowanego preparatu oraz terminu poboru próbek, użyto modeli mieszanych z wykorzystaniem biblioteki lme4 dla środowiska R (Bates i wsp. 2015; R Core Team 2016). 
Do modelowania jako efekty stałe włączono zabiegi herbicydami oraz termin poboru prób ( $\mathrm{z}$ interakcjami). Jako efekty losowe przyjęto powtórzenia pomiarów na poletkach doświadczalnych.

Wizualna kontrola wartości resztkowych nie wykazała oczywistych odchyleń od założeń: homoskedastyczności i normalności. Wartości p (prawdopodobieństwo popełnienia błędu I rodzaju) uzyskano na podstawie testu ilorazu wiarygodności (likelihood ratio test), w którym przeciwstawiono sobie modele: maksymalny (gdzie termin i zabieg były efektami stałymi) i model uproszczony (gdzie tylko termin lub tylko zabieg był efektem stałym).

W następnym etapie przeprowadzono test post hoc przy użyciu testu par z poprawką Tukeya z biblioteki lsmeans (Lenth 2016).

\section{Wyniki i dyskusja / Results and discussion}

Nowoczesne rolnictwo, poprzez stosowanie środków ochrony roślin, może przyczyniać się do wystąpienia w roślinie stresu abiotycznego (Devine i Shukla 2000). Konsekwencją wystąpienia takiego stresu może być ograniczona produkcja fotosyntetyczna, degradacja chlorofili, a także konieczność uruchomienia przez rośliny procesów związanych $\mathrm{z}$ adaptacją do niekorzystnych warunków środowiskowych (Starck 2008).
Przeprowadzone zabiegi ochrony roślin, jak i termin poboru prób mogą wpływać na zawartość chlorofilu w liściach jęczmienia jarego (odpowiednio - chi-kwadrat $=16,16, \mathrm{p}=0,04, \mathrm{df}=8 \mathrm{i}$ chi-kwadrat $=35,75, \mathrm{p}<0,001$, df $=8$ ). Estymacja wyrazu wolnego (tab. 1) również pokazuje takie zależności w parze kontrola/zabieg od terminu (po $24 \mathrm{~h}$ od zabiegu obliczenia zostały wykonane jako różnica pomiędzy kontrolą i zabiegiem; po $72 \mathrm{~h}$ obliczenia wykonano jako (kontrola/24 h-kontrola/72 h)-(zabieg/24 h-zabieg/72 h), które są dwukrotnie niższe od błędu standardowego (SE). Największe różnice zostały zaobserwowane pomiędzy kontrolą a zabiegiem dla Ch300 (-0,051+/-0,023 $\mathrm{SE})$ oraz Ch600 (-0,039+/-0,025 SE) po $24 \mathrm{~h}$ od zabiegu. Najmniejsze różnice wystąpiły pomiędzy kontrolą a ETQ $(0,005+/-0,024 \mathrm{SE})$. Natomiast po $72 \mathrm{~h}$ różnice pomiędzy odpowiednimi zabiegami i kontrolą były najwyższe dla Ch300 $(-0,035+/-0,025 \mathrm{SE})$, a najniższe dla DDA $>-0,001+/-0,024 \mathrm{SE})$.

Porównanie par przy użyciu testu post hoc z poprawką Tukeya potwierdza znaczące zmiany w zawartości chlorofilu dla każdego zabiegu $\mathrm{z}$ osobna od terminu poboru prób (tab. 2). Natomiast nie zaobserwowano żadnych znaczących zmian w zawartości chlorofilu po $24 \mathrm{~h}$ od przeprowadzonego zabiegu MCPA oraz HILs. Różnice takie były widoczne po $72 \mathrm{~h}$ dla par: kontrola/Ch300, Ch300/DDA oraz Ch300/ETQ (tab. 3).

Tabela 1. Wartość statystyki, błąd standardowy dla oszacowanych średnich pomiędzy zabiegiem a kontrolą po 24 h od zabiegu, średnia (wyraz wolny). Po $72 \mathrm{~h}$ obliczenia wykonano jako (kontrola/24h-kontroal/72h)-(zabieg/24h-zabieg/72h)

Table 1. The statistic value, standard error for estimated mean between treatment and control for (time 1). For time 2 the calculations were made as (control:T1-control:T2)-(treatment:T1-treatment:T2)

\begin{tabular}{l|c|c|c|c|c|c}
\hline & \multicolumn{3}{|c|}{ Termin 1 $(24 \mathrm{~h})-$ Time 1 $(24 \mathrm{~h})$} & \multicolumn{3}{c}{ Termin 2 $(72 \mathrm{~h})-$ Time 2 $(72 \mathrm{~h})$} \\
\hline Zabieg - Treatment & estimate & SE & $\mathrm{t}$ & estimate & SE & $\mathrm{t}$ \\
\hline Kontrola - Control & 0,418 & 0,016 & 26,003 & 0,080 & 0,017 & 4,671 \\
\hline Ch300 & $-0,051$ & 0,023 & $-2,253$ & $-0,035$ & 0,025 & $-1,361$ \\
\hline Ch600 & $-0,039$ & 0,025 & $-1,597$ & $-0,006$ & 0,026 & $-0,237$ \\
\hline DDA & $-0,016$ & 0,023 & $-0,692$ & 0,001 & 0,024 & 0,031 \\
\hline ETQ & $-0,005$ & 0,024 & $-0,210$ & 0,025 & 0,027 & 0,925 \\
\hline
\end{tabular}

CH300 - Chwastox Extra 300 SL, Ch600- Chwastox AS 600 EC, DDA - [DDA][MCPA], ETQ - [Etq O-12][MCPA]

estimate - oszacowanie średniej, SE - błąd standardowy, t - wartość statystyki

Table 2. Porównanie par z poprawką Tukeya dla różnic pomiędzy zawartością chlorofilu po 24 i $72 \mathrm{~h}$

Table 2. Pairwise comparisons with Tukey's adjustment for differences between the content of chlorophyll after 24 and $72 \mathrm{~h}$

\begin{tabular}{l|c|c|c|c}
\hline & Difference & SE & t ratio & $p$ \\
\hline Kontrola-Control & $-0,080$ & 0,017 & $-4,671$ & 0,000 \\
\hline Ch300 & $-0,045$ & 0,019 & $-2,365$ & 0,031 \\
\hline Ch600 & $-0,073$ & 0,020 & $-3,731$ & 0,002 \\
\hline DDA & $-0,080$ & 0,017 & $-4,715$ & 0,000 \\
\hline ETQ & $-0,105$ & 0,021 & $-4,921$ & 0,000 \\
\hline
\end{tabular}

CH300 - Chwastox Extra 300 SL, Ch600- Chwastox AS 600 EC, DDA - [DDA][MCPA], ETQ - [Etq O-12][MCPA]

Difference - różnice między średnimi, SE - błąd standardowy, t ratio - stosunek średnicy do błędu standardowego, $\mathrm{p}$ - prawdopodobieństwo popełnienia błędu I rodzaju 
Table 3. Porównanie par z poprawką Tukeya dla różnic pomiędzy zabiegami MCPA i HILs

Table 3. Pairwise comparisons with Tukey's adjustment for difference between treatments of MCPA and HILs

\begin{tabular}{|c|c|c|c|c|c|c|c|c|}
\hline & \multicolumn{4}{|c|}{ Termin $1(24$ h) - Time $1(24$ h) } & \multicolumn{4}{|c|}{ Termin $2(72 \mathrm{~h})-$ Time $2(72 \mathrm{~h})$} \\
\hline Kontrast - Contrast & dif. & SE & $\mathrm{t}$ ratio & $\mathrm{p}$ & dif. & SE & t ratio & $\mathrm{p}$ \\
\hline Kontrola - Control - Ch300 & 0,051 & 0,023 & 2,253 & 0,190 & 0,086 & 0,024 & 3,546 & 0,010 \\
\hline Kontrola - Control - Ch600 & 0,039 & 0,025 & 1,597 & 0,511 & 0,045 & 0,025 & 1,848 & 0,367 \\
\hline Kontrola - Control - DDA & 0,016 & 0,023 & 0,692 & 0,957 & 0,015 & 0,023 & 0,659 & 0,963 \\
\hline Kontrola - Control - ETQ & 0,005 & 0,024 & 0,210 & 1,000 & $-0,020$ & 0,024 & $-0,828$ & 0,920 \\
\hline Ch300 - Ch600 & $-0,012$ & 0,025 & $-0,488$ & 0,988 & $-0,041$ & 0,026 & $-1,561$ & 0,532 \\
\hline Ch300 - DDA & $-0,036$ & 0,023 & $-1,561$ & 0,533 & $-0,071$ & 0,024 & $-2,927$ & 0,046 \\
\hline Ch300 - ETQ & $-0,046$ & 0,024 & $-1,902$ & 0,337 & $-0,106$ & 0,026 & $-4,133$ & 0,002 \\
\hline Ch600 - DDA & $-0,024$ & 0,025 & $-0,956$ & 0,872 & $-0,030$ & 0,025 & $-1,238$ & 0,730 \\
\hline Ch600 - ETQ & $-0,034$ & 0,026 & $-1,315$ & 0,685 & $-0,066$ & 0,026 & $-2,522$ & 0,112 \\
\hline DDA - ETQ & $-0,011$ & 0,024 & $-0,439$ & 0,992 & $-0,035$ & 0,024 & $-1,447$ & 0,603 \\
\hline
\end{tabular}

CH300 - Chwastox Extra 300 SL, Ch600- Chwastox AS 600 EC, DDA - [DDA][MCPA], ETQ - [Etq O-12][MCPA]

dif. -różnice między średnimi, SE - błąd standardowy, t ratio - stosunek średnicy do błędu standardowego, p - prawdopodobieństwo popełnienia błędu I rodzaju

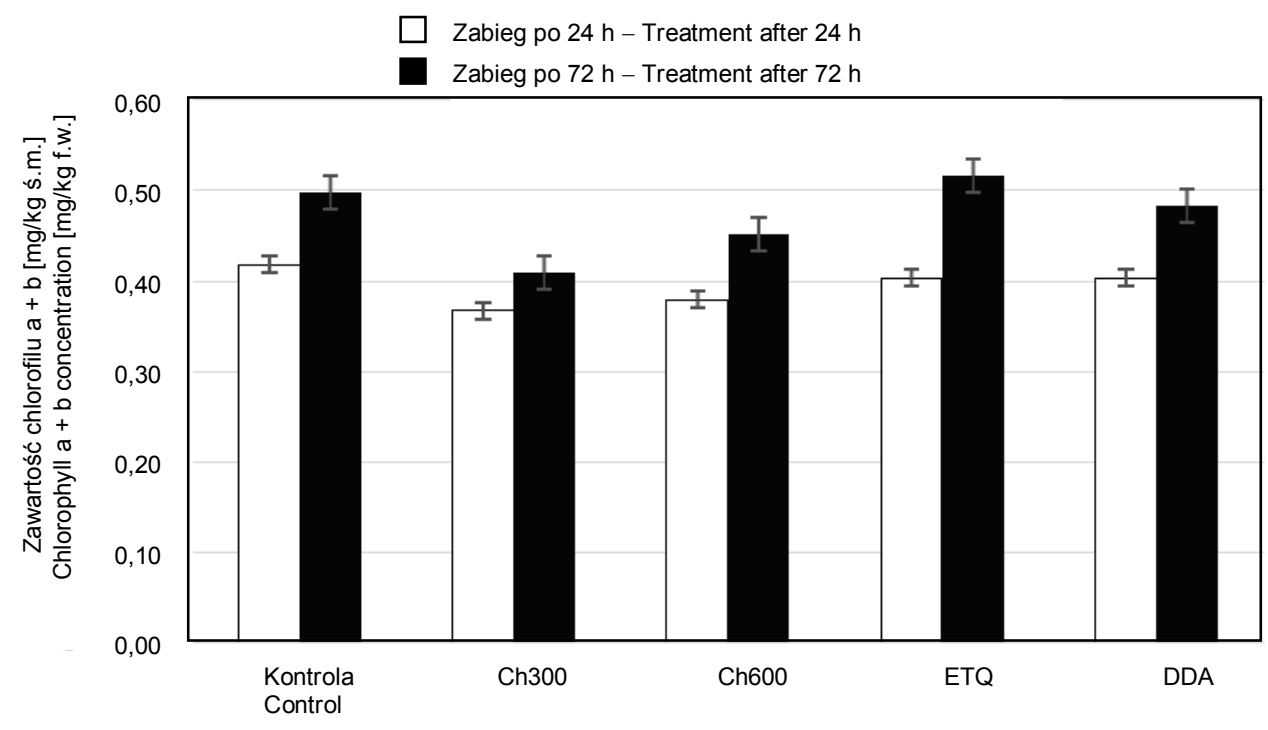

Ch300 - Chwastox Extra 300 SL, Ch600 - Chwastox AS 600 EC, ETQ - [Etq-O12][MCPA], DDA - [DDA][MCPA]

Rys. 1. Zawartość chlorofilu a $+\mathrm{b}$ w liściach jęczmienia jarego po 24 i 72 h od zastosowanego zabiegu Ch300, Ch600 oraz HILs Fig. 1. Chlorophyll $\mathrm{a}+\mathrm{b}$ content in leaves of spring barley after treatment of Ch300, Ch600 and HILs after 24 and $72 \mathrm{~h}$

Z przeprowadzonego doświadczenia wynika, że stosowanie powszechnie dostępnych środków ochrony roślin na bazie MCPA po $24 \mathrm{~h}$ od aplikacji nie powoduje znaczących zmian w zawartości chlorofilu $\mathrm{a}+\mathrm{b}$ w liściach jęczmienia jarego. Natomiast różnice takie zaobserwowano po 72 h dla Ch300, gdzie spadek zawartości chlorofilu $\mathrm{a}+\mathrm{b}$ w porównaniu $\mathrm{z}$ próbą kontrolną wyniósł około $17,8 \%$. W porównaniu do ETQ ta różnica wyniosła $20 \%$, a dla DDA niecałe 15\%. Po zastosowaniu Ch600 72 h po zabiegu opryskiwania różnica $\mathrm{w}$ porównaniu do kontroli wyniosła 9,1\%. W zestawieniu z ETQ różnica ta wyniosła ok. $12 \%$, a z DDA niecałe $6 \%$ (rys. 1 ).

Wyniki przeprowadzonych badań wskazują, że stosowanie komercyjnych środków ochrony roślin na bazie
MCPA oraz nowych HILs nie wywarło znaczącego wpływu na zawartość chlorofilu $\mathrm{a}+\mathrm{b}$ w liściach jęczmienia jarego po $24 \mathrm{i} 72 \mathrm{~h}$ od zastosowanego opryskiwania. Różnice $\mathrm{w}$ zawartości chlorofilu $\mathrm{a}+\mathrm{b}$ w porównaniu do kontroli dla zastosowanych środków ochrony roślin na bazie MCPA po $24 \mathrm{~h}$ wynosiły około $10 \%$, natomiast dla HILs około $3 \%$ i były nieistotne statystycznie.

Największe różnice stwierdzono jedynie po $72 \mathrm{~h}$ dla Ch300 w porównaniu do kontroli, ETQ oraz DDA. Mogą one wynikać z większej tendencji MCPA do wiązania kationów metali dwuwartościowych, a tym samym blokowania ich dostępności dla roślin (Kobyłecka i Skiba 2008; Grobela 2016). Jednakże do uściślenia tych zależności potrzebne są bardziej szczegółowe prace badawcze. 
Uzyskane wyniki w prowadzonym doświadczeniu korespondują z badaniami Tatarkovej i wsp. (2013), Žaltauskaitė i Kišonaitè (2014) oraz Łozowickiej i wsp. (2016), gdzie zastosowanie MCPA w ochronie roślin nie powoduje znaczącego obniżenia zawartości chlorofilu w liściach słonecznika, pszenicy i jęczmienia jarego. Jednakże zastosowanie HILs w sposób jednoznaczny pokazuje, że różnice w zawartości chlorofilu na poziomie $10 \%$ mogą być zniwelowane.

\section{Wnioski / Conclusions}

1. Zawartość chlorofilu $\mathrm{a}+\mathrm{b}$ w liściach jęczmienia jarego po $24 \mathrm{~h}$ od zastosowania środków ochrony roślin na bazie MCPA była niższa o ok. $10 \% \mathrm{w}$ porównaniu do kontroli, natomiast po dobie od zastosowania HILs różnica ta wyniosła $3 \%$. W obu przypadkach rozbieżności były nieistotne statystycznie.

2. Największe spadki zawartości chlorofilu $\mathrm{a}+\mathrm{b}$ zaobserwowano po $72 \mathrm{~h}$ od opryskiwania Ch300 oraz Ch600. Różnice wynosiły odpowiednio 18\% i 10\% w stosunku do kontroli. Zmiany wywołane przez HILs były nieistotne i zbliżone do wartości uzyskanych na obiektach kontrolnych.

3. W przeprowadzonych badaniach zastosowanie komercyjnych środków ochrony roślin na bazie MCPA oraz preparatów typu HILs nie powodowało statystycznie istotnych zmian w ilości chlorofilu $\mathrm{a}+\mathrm{b}$ w liściach badanej rośliny. Pomimo braku statystycznych różnic zastosowanie HILs wywierało mniej negatywny wpływ na badane parametry $\mathrm{w}$ jęczmieniu jarym niż użycie standardowych formulacji.

\section{Literatura / References}

Arnon D.I., Allen M.B., Whatley F.R. 1956. Photosynthesis by isolated chloroplasts IV. General concept and comparison of three photochemical reactions. Biochimica et Biophysica Acta 20: 449-461.

Bates D., Maechler M., Bolker B., Walker S. 2015. Fitting linear mixed-effects models using lme4. Journal of Statistical Software 67 (1): $1-48$.

Ceylan Y., Kutman U.B., Mengutay M., Cakmak I. 2016. Magnesium applications to growth medium and foliage affect the starch distribution, increase the grain size and improve the seed germination in wheat. Plant Soil $406(1-2): 145-156$.

Devine M.D., Shukla A. 2000. Altered target sites as a mechanism of herbicide resistance. Crop Protection 19 (8-10): 881-889.

Ekmekci Y., Terzioglu S. 2005. Effects of oxidative stress induced by paraquat on wild and cultivated wheats. Pesticide Biochemistry and Physiology 83 (2-3): 69-81.

Grobela M. 2016. Differences in the uptake of $\mathrm{Mn}, \mathrm{Zn}$, and $\mathrm{Cu}$ by Hordeum vulgare L. following applications of MCPA-based herbicides and their ionic liquid forms. Polish Journal of Environmental Studies 25 (5): 1931-1936.

Hough W.L., Smiglak M., Rodríguez H., Swatloski R.P., Spear S.K., Daly D.T., Pernak J., Grisel J.E., Carliss R.D., Soutullo M.D., Davis J.H. Jr., Rogers R.D. 2007. The third evolution of ionic liquids: active pharmaceutical ingredients. New Journal of Chemistry 31 (8): 1429-1436.

Kobyłecka J., Skiba E. 2008. The effect of phenoxyacetic herbicides on the uptake of copper, zinc and manganese by Triticum aestivum L. Polish Journal of Environmental Studies 17 (6): 895-901.

Lenth R.V. 2016. Least-squares means: the R package lsmeans. Journal of Statistical Software 69: 1-33.

Lichtenthaler H.K., Wellburn A.R. 1983. Determinations of total carotenoids and chlorophylls a and b of leaf extracts in different solvents. Biochemical Society Transactions 11 (5): 591-592.

Łozowicka B., Wołejko E., Konecki R. 2016. Influence of selected active substances of fungicides and herbicides and time of their application on chlorophyll content in Triticum aestivum L. [Wpływ wybranych substancji czynnych fungicydów, herbicydów i ich terminów aplikacji na poziom barwników asymilacyjnych w Triticum aestivum L.]. Progress in Plant Protection 56 (2): 186-190.

Pernak J., Niemczyk M., Zakrocka K., Praczyk T. 2013. Herbicidal ionic liquid with dual-function. Tetrahedron 69 (38): $8132-8136$.

Pernak J., Syguda A., Janiszewska D., Materna K., Praczyk T. 2011. Ionic liquids with herbicidal anions. Tetrahedron 67 (26): $4838-4844$.

Politycka B. 2007. Plant productivity. Produktywność roślin. s. 353-372. W: „Fizjologia roślin - od teorii do nauk stosowanych” (M. Kozłowska, red.). PWRiL, Poznań, 544 ss.

Praczyk T., Kardasz P., Jakubiak E., Syguda A., Materna K., Pernak J. 2012. Herbicidal ionic liquids with 2,4-D. Weed Science 60 (2): $189-192$.

R Core Team 2016. R: A language and environment for statistical computing. R Foundation for Statistical Computing, Vienna, Austria. https://www.R-project.org [Accessed: 14.12.2016].

Shamshina J.L., Kelley S.P., Gurau G., Rogers R.D. 2015. Chemistry: Develop ionic liquid drugs. Nature 528 (7581): $188-189$.

Starck Z. 2008. Stresses provoked by incorrect nitrogen nutrition in plants. [Stresy wynikające z nieprawidłowego odżywiania roślin azotem]. Postępy Nauk Rolniczych 60 (1): 27-42.

Tatagiba S.D., DaMatta F.M., Rodrigues F.A. 2016. Magnesium decreases leaf scald symptoms on rice leaves and preserves their photosynthetic performance. Plant Physiology and Biochemistry 108: 49-56.

Tatarková V., Hiller E., Vaculík M. 2013. Impact of wheat straw biochar addition to soil on the sorption, leaching, dissipation of the herbicide (4-chloro-2-methylphenoxy)acetic acid and the growth of sunflower (Helianthus annuus L.). Ecotoxicology and Environmental Safety 92: 215-221.

Tränkner M., Jákli B., Tavakol E., Geilfus Ch., Cakmak I., Dittert K., Senbayram M. 2016. Magnesium deficiency decreases biomass water-use efficiency and increases leaf water-use efficiency and oxidative stress in barley plants. Plant Soil 406 (1-2): 409-423.

Wang M., Zhou Q. 2006. Effects of herbicide chlorimuron-ethyl on physiological mechanisms in wheat (Triticum aestivum L.). Ecotoxicology and Environmental Safety 64 (2): 190-197.

Žaltauskaitė J., Brazaitytė V. 2013. Assessment of the effects of sulfonylureas herbicide midosulfuron application on target and non-target organisms. Fresenius Environmental Bulletin 22 (7 A): 1977-1982.

Žaltauskaitė J., Kišonaitė G. 2014. The effects of phenoxy herbicide MCPA on non-target vegetation in spring wheat (Triticum aestivum L.) culture. Biologija 60 (3): 148-154. 